\title{
Comparison of Simple Lumbar Inter Body Fusion with Circumferential Fusion for Treatment of Isthmic Spondylolisthesis
}

\author{
Gazi Shahinur Akter, Md Zakirul Hasan, Dur E Shehvar Sana, Saiful Islam Nayem, Md Shoriful Islam and Mohammad \\ Abdul Mazid*
}

Jinggangshan University, China

*Corresponding author: Mohammad Abdul Mazid, Jinggangshan University, 28 Xueyuan Road, Qingyuan District, Jian-343009, Jiangxi Sheng, China

Submission: 阱 October 15, 2017; Published: 眥 April 17, 2018

\section{Abstract}

Purpose: Spondylolisthesis is a common cause of surgery in patients with lower back pain. Although inter body fusion and circumferential fusion are a relatively common surgical method for the treatment of spondylolisthesis, we retrospectively compared surgical reduction or fusion in situ with simple lumbar inter body fusion (PLIF/TLIF) and circumferential fusion (PLF+TLIF/PLIF) for adult isthmic spondylolisthesis in terms of surgical invasiveness, clinical and radio graphical outcomes, and complications.

Methods: From January 2013 to June 2015, 84 adult patients with isthmic spondylolisthesis who underwent surgical treatment in our department were randomized to simple lumbar inter body fusion (PLIF/TLIF) group (group 1, n=45) and circumferential fusion (PLF+TLIF/PLIF) group (group 2 , $\mathrm{n}=39$ ), and followed up for average 28.6 months (range 24-54 months). All patients of both groups had low back pain as their predominant symptom, with varying degree of radicular pain and neurological symptoms. The data collected retrospectively for analysis were: duration of symptoms, levels of fusion, revision surgery, clinical and radiographic results after surgery, and complications.

Result: All the 84 patients compared in two surgical approaches for IS were included in this retrospective studies. In our analysis, for the surgical management of isthmic spondylolisthesis, we indicated that both approaches lumbar inter body fusion (PLIF/TLIF) and circumferential fusion (PLF+TLIF/PLIF) have equal significant, greater fusion rates with successful clinical outcomes.

Conclusion: Our clinical experience along with statistic findings indicates that in conclusion, there was no significant difference was found between simple inter body fusion (PLIF/TLIF) compared to circumferential fusion (PLF+TLIF/PLIF). Moreover, both techniques led to similar surgical outcomes and complication during follow-up. Thus, these results suggest that both procedures are equally effective for the treatment of isthmic spondylolisthesis.

Keywords: Spinal fusion; Isthmic spondylolisthesis; Posterior lumbar inter body fusion (PLIF); Transforaminal lumbar inter body fusion (TLIF); Postero lateral fusion (PLF)

\section{Introduction}

\section{Background}

Spinal fusion technique was introduced 70 years ago for the treatment of degenerative disc disease and chronic lower back pain [1]. Hibbs \& Albee [2,3] were two spine surgeons in 1911, who performed first spinal stabilization surgery. Forward displacement of a vertebral bone in sequence of normal alignment of vertebra is called Isthmic Spondylolisthesis-most commonly due to progressive vertebral body malalignment in the lumbar region of spine. Even in severe case of spondylolisthesis, the slipped vertebra is comfortably reduced by the modern surgical techniques [4-7].

However, these operations have high risk of neurological complications from the implant and screws, even in correct procedure there are neurological complications [8]. There are no significant neurological complication differences found between the reduction procedure and fusion situ [5,8-10]. About $90 \%$ of all vertebral body slips due to the degenerative and isthmic types of spondylolisthesis [11]. Generally in population after the forth decades $20.7 \%$ are affected [12], lumbosacral junction at lumber 5 and sacrum 1 (L5-S1) are mostly affected.

Types of spondylolisthesis include: pathologic, isthmic, congenital, post-operative, traumatic, and degenerative [13] Deformity are associated with collision of nerve root from its original place, which results in neurological symptoms and degenerative changes [14]. Isthmic Spondylolisthesis treatment depends upon the severity of its symptoms. Treatment of choice 
for mild Spondylolisthesis is physical therapy, non-steroidal antiinflammatory drugs, and modification of patents deli activities, which makes patients, feel comfortable from pain and rest for 10-20days [14]. After adults fail to respond up to 3-6 months of conservative management, operative management is required [15].

The main aim of treatment is nerve root and spinal canal decompression, stabilization of motion segment, restoration of disk space height and correction of deformity [16] Stabilization of motion segment is the key point to keep persistent curative effects. Various fusional procedures, including Transforaminal lumbar inter body fusion (TLIF), posterior lumbar inter body fusion (PLIF), postero lateral fusion (PLF), and circumferential fusion (PLF+TLIF/PLIF) are recommended for the treatment of Isthmic spondylolisthesis symptoms [15]. Inter body and Postero lateral fusion are the two basic fusion methods to keep permanent stabilization of vertebral column. Many physicians have long debated on the techniques of spinal fusion. According to report the clinical success rate of modern bilateral postero lateral fusion (PLF) is about $81-100 \%$ and $60-98 \%$ clinical success rate $[17,18]$ in Comparision to the rate of transpedicular fixation [19].

Theoretically, circumferential fusion can release the disc space compression, by adding end plate there is increase in fusion rate, and it can improve deformity correction. Adult with Isthmic Spondylolisthesis fusion rate significantly varies from $74-98 \%$ in Transforaminal lumber inter body fusion (TLIF/PLIF) technique [18]. Thus, in this study, we compared Patients who came in our hospital with the complain of lower back pain and signs and symptoms of lumbar isthmic spondylolisthesis who were treated by either simple TLIF/PLIF alone, or PLF+TLIF/PLIF to assess whether patients treated with TLIF/PLIF alone demonstrated a high rate of complication, compared with those treated with PLF+TLIF/PLIF.

\section{Spine anatomy}

The spine that supports the body's upper weight provides posture that allows movement and flexibility and protects the spinal cord. It stretches down the midline from the trunk to the base of the skull to the coccyx. Known as the vertebral column, the spinal column is a combination of 26 bones in adults out of which 24 separate vertebrae is interspaced with cartilage except for the sacrum and coccyx. During growth in adolescence, Spine consists of 33 bones, as five bones of sacrum and four bones of coccyx do not fuse together until adolescence. The vertebrae are termed according to their first letter of their anatomical region. I.e. Cervical, Thoracic or Lumbar and they are given numbers to indicate their position. For example, L5 is given to the fifth lumbar vertebrae because it is the most inferior one and lies beneath the fourth lumbar vertebrae. Each and every vertebra has its own important part and they are: vertebral foramen, the body, transverse process, and spinous process.

A. A hollow space that contains the spinal cord and meninges lies below the transverse processes and spinous process that are between the body.
B. There are thin columns of bone that point out to the left and right sides of the body, which are termed, the transverse process.

C. The main weight-bearing region of a vertebra is the body, which makes up the bulk of the bones mass.

D. Posteriorly, the spinous process elongates from the edge of transverse process. Inter vertebral discs are thin regions of cartilage, which lies between the vertebrae of spine. Inter vertebral discs are comprised of an outer layer known as the annulus fibrosus and a soft, pulpy region known as the nucleus pulpous in the middle.

E. The inner nucleus pulpous acts as a shock absorber to support the body's weight and prevents the vertebrae from painfully crashing into each other while under strain. To provide shock absorption to the body's weight, inner nucleus pulpous prevents the vertebrae from crashing into each other during strain.

F. The annulus fibrosus, which is comprised of a stout fibro cartilage, binds the vertebrae together and is flexible enough to allow for movements.

The protection of spinal cord is facilitated by the alignment of the vertebrae, which forms a hollow, bony tube preventing it from damage and infection. These small spaces known as inter vertebral canal allows spinal nerves to pass through the spinal cord and extend to other parts of the body.

\section{Lumbar spine}

A lumbar vertebra is comprised of five cylindrical individual bones, which forms the spine in the lower back. They help carry all of the upper limb weight and provide flexibility and motility to the base region. It also protects the spinal cord and nerves within its periphery. Based at the midline of the body in the lumbar region, the lumbar vertebrae make up the region of the spine inferior to the thoracic vertebrae in the thorax, superior to the sacrum and coccyx in the pelvis. They are aligned to make up a column, which are in order from L1 to L5-First lumbar vertebrae to the fifth lumbar vertebrae, together, which create the lumbar curvature in the lower back.

Inter vertebral disc are formed of strong fibro cartilage with a jelly like center, which connects individual vertebrae to its surrounding vertebrae. Annulus Fibrosus, the outer layer of inter vertebral disc holds the vertebrae together and provides strength, rigidity and mobility to the back during movement. For shock absorption, nucleus pulpous acts as a shock absorber to resist strain and pressure on the lower back.

The largest and the heaviest vertebrae in the spine or the lumbar vertebrae are second to size only to the sacrum. A cylinder of bones known as vertebral body that bears most of the body's weight makes up majority of the lumbar vertebrae mass. The body is posteriorly connected to thin ring of bone known as arch that surrounds the hollow vertebral foramen and joins the body to the bony processes 
posteriorly. The vertebral foramen is a big, triangular opening that allows space for the spinal cord, cauda equina and meninges for the ease of their passage through the lower back.

Several bony processes that extend from the vertebral arch provide muscle attachment and mobility of the lower back. The spinous process, which is a thin rectangle of bone, extends from the posterior end of the arch, which builds a connection point for the muscles of the back and pelvis such as the psoas major and inter spinal. The transverse process which are short and triangular are on the left and right lateral side which forms vital connecting points for variety of muscles including the rotator and multi fidus muscles which are responsible for extension and rotation of the trunk.

Lumbar vertebrae lack the transverse foramina in the transverse process irrespective of the cervical vertebrae in the neck. It also lacks facets to either side of the body. The L5 vertebra is distinct from its other neighbors (L1-4) being much larger on its front side than in the back. On the other hand, Spinous process is smaller than in the lumbar vertebrae comprising of its wide, four sided shape that comes to a rough edge and a thick notch.

\section{Sacrum spine}

A large, wedge shaped vertebrae of the spine at the inferior end is the Sacrum. It builds a solid base of the spinal column intersecting with the hipbones to give rise to the Pelvis. It is a very stout and supports the upper body weight as it spreads across the pelvis and into the legs. During the late adolescence and early adulthood, the sacrum forms five individual vertebrate to form a single bone around the age of thirty. A ridge of tubercles along the posterior surface of the sacrum represents the spinous processes of these fused bones.

The sacrum forms the fibro cartilaginous lumbosacral joint with the fifth lumbar vertebra above it at its wide superior end The Sacrum extends to appoint at its inferior end forming the fibro cartilaginous sacrococcygeal joint with the tiny coccyx (tail bone). It forms the sacroiliac joints together on the left and right lateral sides, which is built up by numerous ligaments that reduce mobility and also solidifies the pelvis. The sacrum is also concave in structure so as to provide larger area within the pelvic cavity. Male and female sacrum is different in shapes and sizes. Female sacrum is shorter, wider and is curved more posteriorly than the male sacrum to allow more room for the uninterrupted passage of the fetus through the birth canal during birth.

The sacrum has many nerves of the cauda equine at the inferior end, which enters the sacrum from the vertebral foramen of the lumbar vertebrae through a tunnel like sacral canal. From here, the nerves divide and pass through the sacrum via four pair of holes on the sides of the canal, which is also known as sacral foramina, or also through the sacral hiatus at the inferior end of the canal [19].

The sacrum assists various vital functions in the skeletal, muscular, nervous, and female reproductive systems. As a hallmark of the pelvis, it locks the hipbones together posteriorly and supports the base of the spinal column as it junctions with the pelvis. Some other muscles of the hip joint including the gluteus maximums, iliac us and performs origin on its surface and draws it for the mobility of the leg. It also surrounds and protects the nerves of the lower back as they branch their way inferiorly toward the end of the trunk and into the legs. Finally, It helps form the pelvic cavity that provides support and protection to the delicate organs of the abdominopelvic cavity and provides space for a fetus during childbirth.

\section{Fusion Techniques and Options}

\section{Circumferential fusion}

Circumferential fusion can be performed in a variety of manners [20-24] such as Posterior lumbar inter body fusion plus Postero lateral fusion (PLIF+PLF), and transformational lumbar inter body fusion plus Postero lateral fusion (TLIF+PLF). As the necessity of solid fusion is pressed, circumferential fusion is attempted $[25,26]$. It is observed that because the transformation of a grafted bone and loss of reduction after PLF lowers the union rate, good results would be produced when PLF and PLIF are applied together. Radiographic analysis revealed a statistically significantly greater improvement in spondylolisthesis following Circumferential Fusion. However, significantly higher reoperation rate for progression of degenerative disease, mainly attributable to the increased rate of pseudoarthrosis/instrumentation failure, exacerbation of spondylolisthesis, and adjacent segment disease was observed in the PLIF alone cohort statistically.

It is concluded that compared to other different types of fusion, Circumferential Fusion was statistically and significantly associated with decreased odds of reoperation for progression of degenerative diseases [27-29]. The fusion rate after circumferential fusion is higher than that in standalone posterior or anterior procedures, regardless of the method of internal fixation or graft source. Because of this, the relative indication for $360^{\circ}$ is arthrodesis to treat spondylolisthesis stem from its extremely high and reliable fusion rate [30]. These are given below:

A. It provided an edge of perfect stability by reconstruction of all three columns of the spine and optimum decompression of all parts of the spinal canal.

B. It restored lordosis, showed a tendency toward better functional outcome, and resulted in less peak back pain and leg pain and provided a higher union rate with significantly fewer repeat operations.

C. Mechanical factors, such as the difficulty in achieving fusion at the lumbosacral junction or multi leveler throdesis.

D. Postsurgical factors, such as a failed previous fusion, in which the posterior bone healing

E. Capability has already proven itself to be incompetent.

F. Patient related factors, such as diabetes, smoking, orimmuno compromise.

How to cite this article: Gazi S, Md Zakirul H, Dur E S S, Saiful I N, Md Shoriful I, Mohammad A M. Comparison of Simple Lumbar Inter Body Fusion with 


\section{Lumbar inter body fusion}

For the alleviation of back pain, various techniques have been developed for fusing lumbar spine vertebrae. Lumber inter body fusion, being one of them includes posterior lumbar inter body fusion (PLIF), trans foraminal lumbar inter body fusion (TLIF), anterior lumbar inter body fusion (ALIF), and lateral lumbar inter body fusion (LLIF). Cloward in 1940 described it first and put it to popular practice until another modifications were proposed by Lin $[19,31]$ followed by Harms and Rolinger in 1982 who described the TLIF technique for creating a circumferential fusion through a single postero lateral approach [32]. Lumbar surgical fusion procedures have increased by $220 \%$ in 2001 from 1990 after the inter body cages were approved [33]. The factors range an expanding elderly population, introduction of safer, quicker and cost effective lumbar fusion techniques and patients desire to remain active and productive into their senior years.

A. TLIF: (Transforaminal lumbar inter body fusion) is a procedure where a bone graft is used to fuse the spinal vertebrae after disc is eliminated. As in the PLIF procedure, The TLIF procedure also places a single bone graft between the vertebrae from the side, rather than two bone grafts from the rear. The graft is inserted from the side where the facet joint is removed in order to avoid mobility and damage of the nerve roots during the procedure.

B. PLIF: (posterior lumbar inter body fusion) is a surgical procedure which is carried out to remove a source of leg or back pain and fuse spinal vertebrae with bone graft. It is also called posterior procedure as it is conducted by giving an incision on the back approaching the spine. Instrumentation is used to provide space for graft in gand to facilitate stabilizing the spine.

C. LLIF: (Lateral lumbar inter body fusion) also known, as Lateral access spine surgery is a minimally invasive surgery where the spine is accessed from incisions on the side of the body. It is particularly useful as it helps avoid separation of the low back muscles, cutting bone, or moving aside blood vessels as required for other minimally invasive spine fusion procedures (PLIF, TLIF, ALIF). Conditions such as herniations, asymmetric disc generation, nerve impingement, and certain tumors are benefited from this procedure.

D. ALIF: (Anterior lumbar inter body fusion) procedure is performed to eliminate a large portion of a degenerated disc, which acts as a source of leg or back pain. A space is made between the vertebral bodies relieving pressure and creating more space for spinal nerves to passably during the procedure. As its name suggests, it is called so because spine is approached anteriorly or from the front. The removed disc is then replaced with implanted bone grafting materials and the posterior approaches. It helps avoid damage to the adjacent vertebral bodies in the low back to provide support.

\section{Equipments}

Different types of Instrumentation used in Lumber fusion prostheses are included as follows:
A. Inter body Spacers

B. Plates or Rods with Pedicle Screws

C. Trans laminar or Facet Screws

D. Hart shill Rectangles

\section{Materials and Methods}

\section{Patient population}

84 patients with low grade L5-S1, Isthmic spondylolisthesis were allocated in our hospital. 45 patients of mean age 48.2 years with Inter body Fusion Operation and 39 patients of mean age 43.7 years were given circumferential fusion operation at the Second Affiliated Hospital of Anhui Medical University. The date of recruitment was from January 2013 to June 2015.

According to the consecutive sequence of hospitalization, patients were assigned a serial number, and randomly organized to group 1 or group 2. All participants consented. There were 44 males and 42 females, aged 25 to 67 years (Table 1). All patients considered for surgical treatment had low back pain, lower extremity pain or neurological intermittent claudication that were refractory to conservative treatment for lesser than a month.

Table 1: Clinical data for 84 patients undergoing Inter body fusion and circumferential fusion in situ.

\begin{tabular}{|c|c|c|}
\hline Category & Group 1 & Group 2 \\
\hline Total patients & 45 & 39 \\
\hline \multicolumn{3}{|c|}{ Sex } \\
\hline Male & 20 & 22 \\
\hline Female & 25 & 17 \\
\hline $\begin{array}{c}\text { Mean age in years } \\
\text { (range) }\end{array}$ & $48.2(27-67)$ & $43.7(25-62)$ \\
\hline Fusion time (min) & 6.62 & 6.56 \\
\hline Operative time (min) & 166.9 & 189.9 \\
\hline \multicolumn{3}{|c|}{ Meyerding Grade } \\
\hline I & 18 & 17 \\
\hline II & 23 & 19 \\
\hline III & 4 & 3 \\
\hline Blood loss (ml) & 211.1 & 288.4 \\
\hline Post-op drainage $(\mathrm{ml})$ & 144.6 & 193.8 \\
\hline Hospital stay (days) & 14.5 & 15.3 \\
\hline $\begin{array}{l}\text { Follow-up time } \\
\text { (months) }\end{array}$ & 28.6 & 31.2 \\
\hline
\end{tabular}

Those patients who received the Inter body fusion had to satisfy a certain criteria:

A. A diagnosis of low grade isthmic L5-S1 spondylolisthesis (Meyerding grade I or II);

B. An indication for surgery (patients with at least one side neurological symptoms).We excluded patients with a history of previous spinal surgery or lower limb discrepancy. 
The inclusion criteria's of the control group were:

A. Age of 18 or older;

B. No evidence or history of spine problems;

C. No marked lower limb length discrepancy (i.e., $>20 \mathrm{~mm}$ ).

In order to limit a selection bias, Postoperative patients were followed for at least 2 years. The demographic characteristics are listed in (Table 1). The presence of one or two level isthmic spondylolisthesis, patients with persistent pain in the lower extremities and the back who didn't respond to treatment for less or more than 6 months and no coexisting spinal deformity or lumbar surgery were the criteria's. Results of all patients showed Meyerding grade 1 or grade 2 spondylolisthesis. Then, we divided the study population into two groups: inter body fusion alone (TLIF or PLIF cohort, group 1); and Circumferential Fusion (PLF+TLIF/ PLIF cohort, group 2). After Decompression of the posterior spinal elements and instrumentation of the lumbar pedicles no any change was observed.

\section{Outcome Assessment}

After careful retrospective revision of patient records, operative notes, and performing clinical and radiological assessment pre and post operatively, we determined the treatment effectiveness by reporting the patient outcomes. Oswestry Disability Index Score (ODI) and Visual Analogue Scale (VAS) score were used to measure functional and clinical outcomes of immediate postoperative outcome, preoperative latest follow-up radiographs including anterior-posterior and lateral views, Computed Tomography Scanning (CT) and Magnetic Resonance Imaging (MRI). Decision of slip vertebra was made according to Taillard technique and Meyerding grade and standing lateral radiograph [34-36].

Cobb's technique was used to calculate Focal lordosis [37]. Over the rostral vertebral body percentage of the superior endplate was normalize the height of the disk [38]. For Meyerding grade, 35 cases were grade I, 42 were grade II and 7 were grade III.

\section{Pre operative preparation}

Pre-operative routine examination and investigations were done in all patients. These included: Complete Blood Count (CBC), Magnetic Resonance Imaging (MRI), Electro Cardio Gram (ECG), Liver Function Test (LFT), Serology Renal Function Test (RFT), $\mathrm{X}$-ray Lumbar spine anterior-posterior and lateral views, chest X-ray anterior-posterior view, and computed tomography scanning (CT). Preoperative Prophylactic antibiotics were given to the Patients to diminish infection.

\section{Surgical techniques}

Before starting Inter body fusion or Circumferential Fusion procedure, patients were placed properly on Wilson frame in prone position. Preoperative antibiotic cefazolin 2 gram was given intravenously. Under fluoroscopic guidance at the lateral spinous process, a 22-gauge needle was placed into the spinous process. Before giving manual incision at fracture region, $0.5 \%$ of bupivacaine with epinephrine about5-10 $\mathrm{ml}$ was injected into the paraspinal muscles.

\section{Inter body fusion}

In case of inter body fusion, midline approach is preferred. In this approach, exposure is very less which is from lateral to facets due to its intended fusion surface. In this process infra and supraspinous ligaments were taken out and then ligament of falvum was lifted from inferior laminas surface at lower side of cephalad lamina by using curette.

To perform Partial Facetectomies, a burr and Kerrison rongeurs were used to create hemilaminectomy opening to the vertebral disc. Laterally ligament of flavum was released from the facets, cauded and cephalad from the laminas, then retraction of medially based flap against Dura, which protracts traversing root of nerve, is protected underneath the ligamentum flavum flap. Using a blade size of 15, annulotomy defect was created. To remove exposed bleeding and materials of disc curettes, shavers and Pituitaries were used.

After placing a custom funnel into the disc space, cancellous bone graft and auto graft laminectomized bone were packed against the anterior longitudinal ligament (Figure 1-7). For the impeachment of the graft, A PLIF/trans foraminal lumbar inter body fusion polyether ether ketone cage was placed linear through the annular window while preserving the facets.

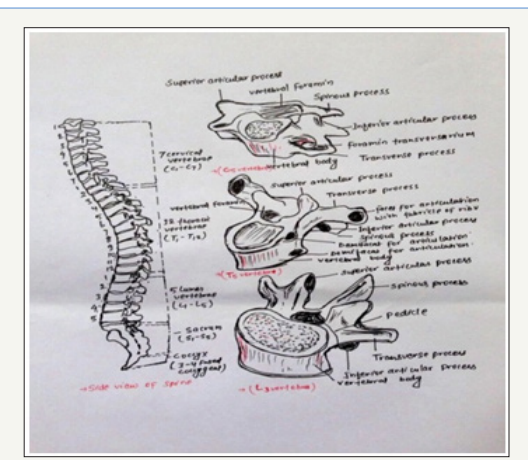

Figure 1: In figure all spinal section and its corresponding vertebrae.

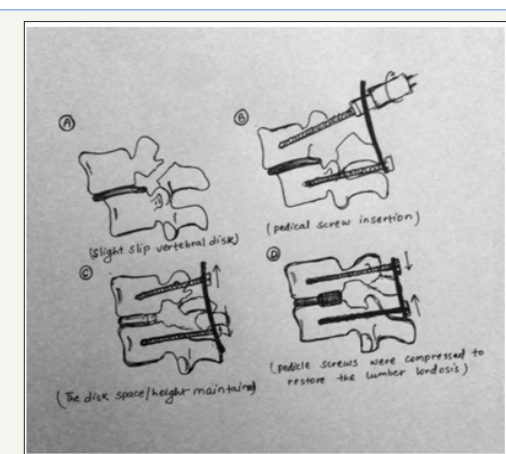

Figure 2: (A) Diagram shows spinal fusion with Inter body Spacers between two vertebral bodies.

(B) Diagram shows spinal fusion with a typical rod and screw device $(\mathrm{C})$ Diagram shows a typical metallic plate and pedicle screws device (D) Diagram shows Translaminar or Facet Screws in vertebral body.

How to cite this article: Gazi S, Md Zakirul H, Dur E S S, Saiful I N, Md Shoriful I, Mohammad A M. Comparison of Simple Lumbar Inter Body Fusion with 


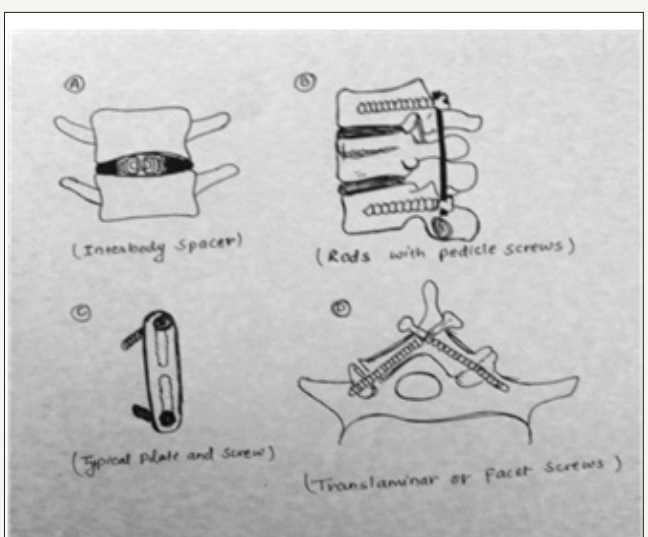

Figure 3: (A) Diagram shows slippage of vertebral disk.

(B) Diagram shows drawing back of the pedicle screws with reduction.

(C) Spinal alignment and inter vertebral disc height mentioned by applying compression against the rods.

(D) Inter body Spacers (PEEK) cages were inserted between the disk space for inter body fusion and the pedicle screws were compressed and Spinal alignment was mentioned.
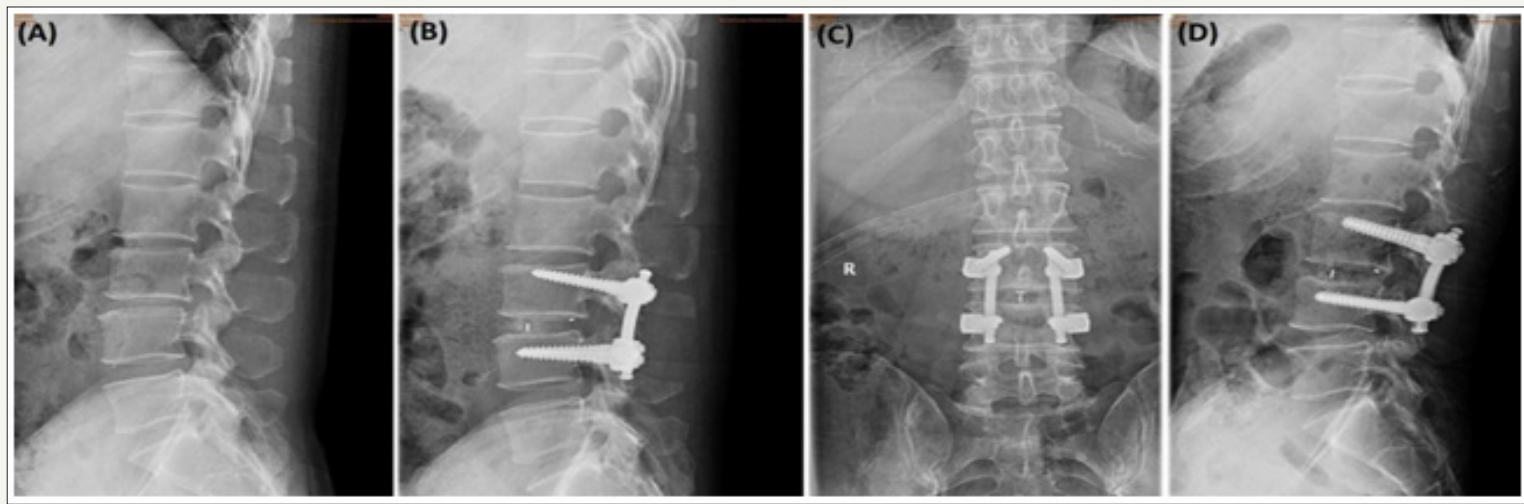

Figure 4: Surgical reduction and PLIF performed in a 42-year-old woman with isthmic spondylolisthesis.

(A) Preoperative lateral X-ray.

(B) Immediate Postoperative lateral X-ray showed that complete reduction of the spondylolisthesis.

(C) 10 months and

(D) 17 month's follow-ups radiographs show significant correction in compare to pre-operative lateral radiograph.
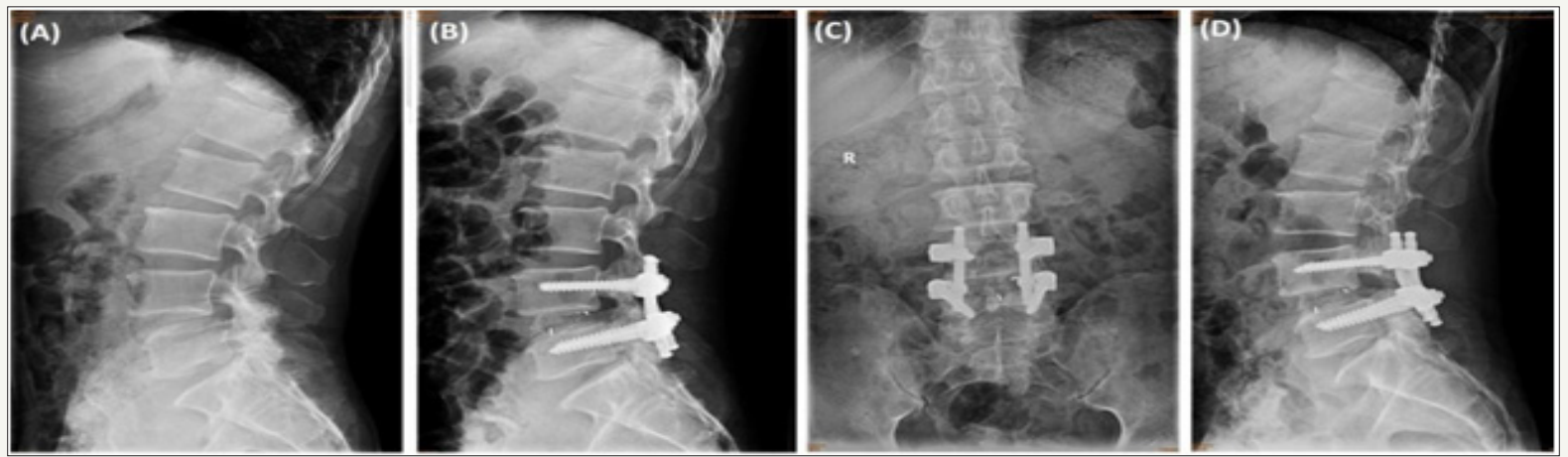

Figure 5: A 57-year-old woman with isthmic spondylolisthesis was surgically treated with PLIF in situ.

(A) Preoperative lateral X-ray showed that slippage was $34.1 \%$ and focal lordosis was -3.0.

(B) Immediate Postoperative lateral X-ray showed that complete reduction of the spondylolisthesis.

(C) 9month follow-up radiographs shows significant improvement in anterior vertebral height and kyphotic deformity.

(D) Final follow-up after 19 months of postoperative with complete reduction of the spondylolisthesis. 

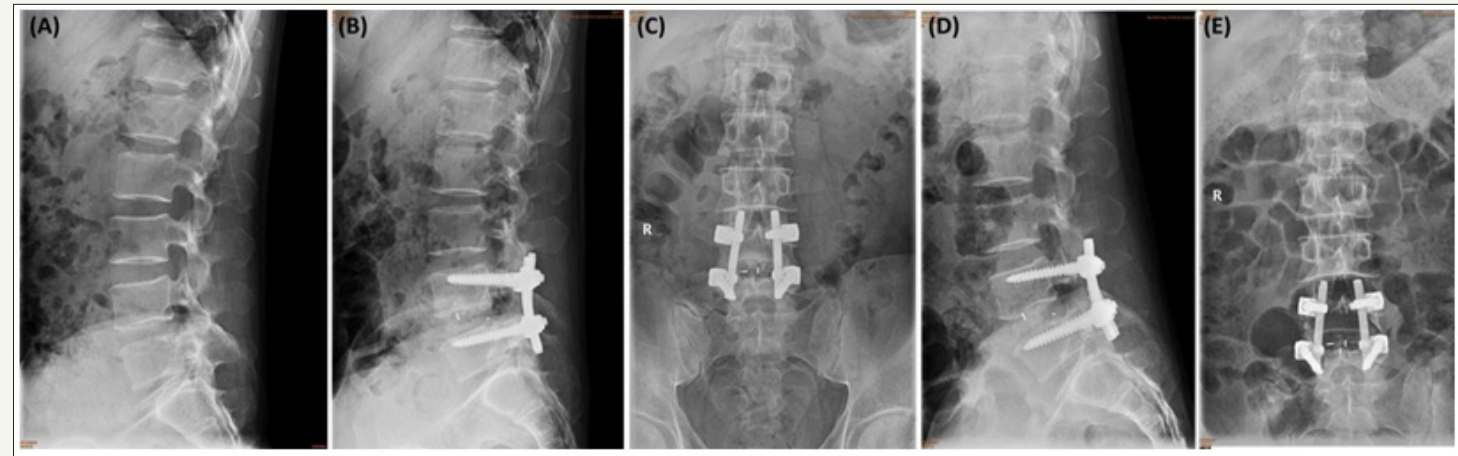

Figure 6: A 56-year-old Man with isthmic spondylolisthesis at L4-L5 level,

(A) Preoperative Lateral radiograph showed that slippage was $23.4 \%$ and focal lordosis was -2.8 .

(B) and (C) Immediate Postoperative lateral and anteroposterior X-ray showed that complete reduction of the spondylolisthesis.

(D) and (E) Final follow-up lateral and anteroposterior X-ray showed that complete reduction of the spondylolisthesis.
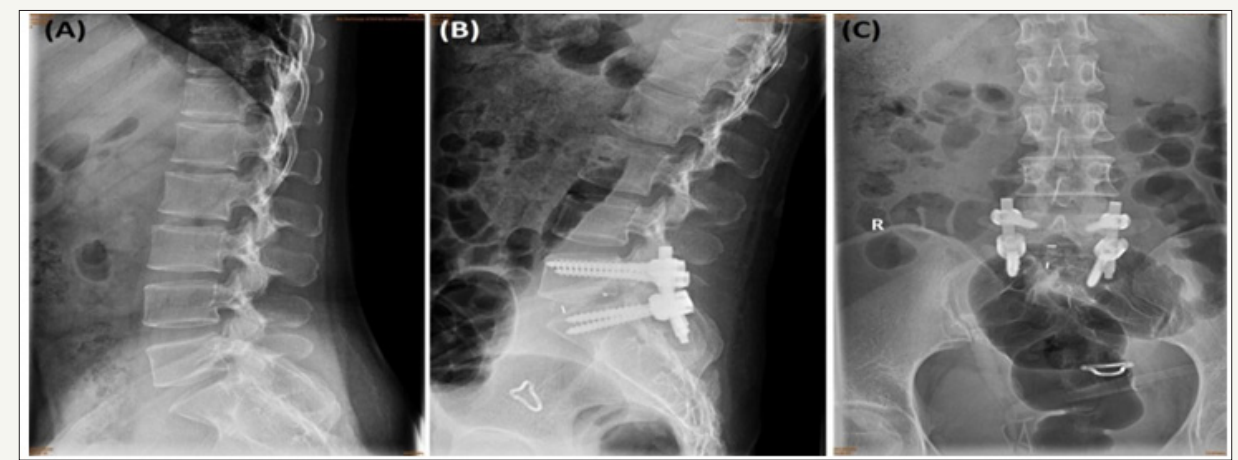

Figure 7: A 48 years old female with isthmic spondylolisthesis at L5-S1 level,

(A) Preoperative Lateral radiograph showed that slippage was $31.6 \%$ and focal lordosis was -2.88 .

(B) and (C) 6 months follow-up lateral and anteroposterior X-ray showed that complete reduction of the spondylolisthesis.

By the help of fluoroscope x-ray radiograph, ultimate position was conformed. After removing facets and ligamentum flavum, complete decompression was achieved. After this, all procedure was observed lumbar spine settled into lordosis angle and Wilson frame was taken out of kyphosis. Finally, Pedicle screw fixation was placed over the facets. Then wound was cleaned and incision was closed in interrupted layers. In some surgical procedures, we put drain and in some we did not.

\section{Circumferential Fusion}

In case of Circumferential Fusion, first of all, patient was placed on a radiolucent spine table. When Kyphosis was detected, Manipulative reduction was applied. By the help of Fluoroscope, fractured vertebral body was located. In this procedure, posterior midline approach was also preferred with midline straight incision at the center of the affected level and laminae was exposed. Both side of facet joint was exposed with the help of electric cautery. At the level below and above fractured vertebral body, Pedicle screws were introduced $[39,40]$.

In case of intact pedicle to decompress the posterior aspect of the calsac both laminae and Spinal process at the affected level are removed by rongeurs. After completing posterior decompression, for restoring the segmental height and realignment of the spinal columns, screws of both sides were distracted axially with contoured longitudinal rods, verified with the help of C-arm x-ray. In cases of laceration, Dura mater was repaired. Anterior surface of the cal sac and posterior longitudinal ligament was released for providing better exposure of inters vertebral discs and posterior vertebral body. Then, by the help of nerve retractor nerve root were gently protected and retracted and vertebral body was removed completely by using "L" angle retro pulshed fragment of the fractured vertebral body, which was placed back into the corpus with the help of hammer. Finally, anterior aspect of the cal sac was decompressed.

After the placement of a custom funnel into the disc space, cancellous bone graft and auto graft laminectomized bone were packed against the anterior longitudinal ligament for the impeachment of the graft, A PLIF/Transforaminal lumbar inter body fusion polyether ether ketone cage was kept straight via the annular window while conserving the facets.

After finishing all of the decompression procedure neural elements involvement was rechecked, placement and tightening of second rod was done. Screwing and Final cages positioning, spinal 
column alignment, and height of vertebral body was observed with the help of fluoroscope. Drain was placed, wound was cleaned and incision was closed in interrupted layers followed by sterile bandage for sterility.

\section{Outcome measures}

VAS (Visual Analog Scale) was used to evaluate pre and postoperative clinical status. (In VAS, $0 \mathrm{~mm}$ means no pain and $100 \mathrm{~mm}$ means un-tolerating pain), ODI (Oswestry Disability Index) and JOA (Japanese Orthopedic Association) score. JOA express recovery rate for functional improvement [41]. Excellent, good, fair, unchanged, and worse were the five satisfactions level recorded [42]. On first post-operative day, neutral lateral x-ray was taken then on $3,6,12,24$ consecutive months extension-flexion positions $\mathrm{x}$ - ray were taken and lumbar spine sagittal alignment and boney fusion were evaluated on the final follow-up. 2D computed tomography (CT) was recommended in case where bone fusion is not clearly visible and observed. Criteria of Radiograph included: bone fusion and bone series, bridging the fusion area $[43,44]$. X-ray and 2D computed tomography (CT) was evaluated independently by one radiologist and two spine surgeons.

\section{Statistical analyses}

For statistical analyses, we have used mean and standard deviation for calculating detail variability, and for categorical variability, frequency analyses were used. Both the groups were compared by X2 analysis and t-test. Paired t-test was used to calculate preoperative and postoperative guidelines. Statistically, significance was considered for P less than 0.05 and $95 \%$ confidence interval. SPSS software was used to perform all the statistical analyses (SPSS, Inc., Chicago, Illinois).

\section{Result}

All the 84 patients of group one and two followed-up for 29 month in average. Total patents in- group 1 was 45 and 39 in-group 2 as the summary of radiological and clinical results are maintained in Table 1. According to patient's age and gender, no significant findings were observed in both groups. Group 1 average operation time was 167 minutes and 190 minutes in group 2, in the same way during surgery average blood loss was $211 \mathrm{ml}$ in group 1 and $211 \mathrm{ml}$ in group 2, which was very similar and not significant to distinguish the result of two different procedures (The detail information is given in Table 1).

\section{Clinical outcomes}

After post-operation, in first week, all the patients of both groups could only walk and sit up with some supports from family members or medical staff. Before operation, VAS score of group 1 and 2 were 7.82 and 8.15 respectively, after post operative duration of 3 months, it decreased to 2.35 and 3.21, in group 1 and 2 respectively, it improved to 1.95 in group 1 and 2.25 in group 2 at the time of final follow-up. (The detail information is given in Table 2). At each time of data collection, the difference between the both groups is not significant. Preoperative ODI scores in-group 1 was found to be 62.56 compared with 63.67 ( $p<0.001)$. When we observed the values after three months postsurgical period, values decreased to 19.95 in group 1 and 25.75 in group 2. A final followup results improved the values to $17.48(\mathrm{p}<0.001)$ in group 1 and 19.35 ( $\mathrm{p}<0.001$ ) in group 2 (Table 2). During each follow-up, no significant differences between the two groups were observed. JOA score was 10.66 in group 1 and 10.41 in group 2 before surgery, 24.33 and 21.79 at 3 months post-surgically, and 24.95 and 23.74 at final-follow up, respectively (Table 2). No such data of significance were noted in both groups. The postoperative improvement rate was $74.46 \%$ in group 1 and $60.92 \%$ in group 2 in the final analysis, without significant difference $(\mathrm{p}=0.565)$.

Table 2: VAS, ODI and JOA of the two groups.

\begin{tabular}{|c|c|c|c|}
\hline & Group I & Group II & P \\
\hline \multicolumn{4}{|c|}{ Amount of Slipping(\%) } \\
\hline Pre-op & $28.13 \pm 11.87$ & $27.82 \pm 10.85$ & NS \\
\hline Post-op & $17.45 \pm 8.78$ & $6.35 \pm 5.96$ & $<0.001$ \\
\hline Final follow-op & $18.13 \pm 10.10$ & $5.95 \pm 5.86$ & $<0.001$ \\
\hline \multicolumn{4}{|c|}{ Disc Height (\%) } \\
\hline Pre-op & $14.67 \pm 6.44$ & $15.12 \pm 6.30$ & NS \\
\hline Post-op & $25.75 \pm 5.57$ & $28.59 \pm 5.28$ & $<0.05$ \\
\hline Final follow-up & $24.97 \pm 4.87$ & $27.98 \pm 4.90$ & $<0.05$ \\
\hline \multicolumn{4}{|c|}{ Local Lordosis (Degree) } \\
\hline Pre-op & $10.91 \pm 6.10$ & $10.96 \pm 6.27$ & NS \\
\hline Post-op & $14.89 \pm 5.85$ & $21.33 \pm 5.85$ & $<0.005$ \\
\hline
\end{tabular}

Values are mean \pm SD; NS not significant.

\section{Radio logical outcomes}

Spinal fusion was achieved well in all 84 patients without any expulsion of implant cage while in-group1; the average slippage was $28.13 \%$ and $27.82 \%$ in group 2 . At the initial follow-up, both groups decreased significantly to 5.95 and 18.13 in the same way it decreased to 6.35 and 17.45 at its final follow-up visit. At every time of follow-up constantly both group slippage was decreased. Ingroup 1, height of disc in average was $14.67 \%$ and $15.12 \%$ in-group $2(\mathrm{P}=0.583)$. On the final follow-up, it was $24.97 \%$ in group 1 and $27.98 \%$ in group 2 preoperatively (There was no significant loss of inter vertebral space observed in both groups 1 and 2 (Table 3).

Table 3: Radiological outcomes of the two groups.

\begin{tabular}{|c|c|c|c|}
\hline & G roup I & Group II & P \\
\hline \multicolumn{4}{|c|}{ Amount of Slipping(\%) } \\
\hline Pre-op & $28.13 \pm 11.87$ & $27.82 \pm 10.85$ & NS \\
\hline Post-op & $17.45 \pm 8.78$ & $6.35 \pm 5.96$ & $<0.001$ \\
\hline Final follow-op & $18.13 \pm 10.10$ & $5.95 \pm 5.86$ & $<0.001$ \\
\hline \multicolumn{4}{|c|}{ Disc Height (\%) } \\
\hline Pre-op & $14.67 \pm 6.44$ & $15.12 \pm 6.30$ & NS \\
\hline Post-op & $25.75 \pm 5.57$ & $28.59 \pm 5.28$ & $<0.05$ \\
\hline Final follow-up & $24.97 \pm 4.87$ & $27.98 \pm 4.90$ & $<0.05$ \\
\hline
\end{tabular}




\begin{tabular}{|c|c|c|c|}
\hline \multicolumn{4}{|c|}{ Local Lordosis (Degree) } \\
\hline Pre-op & $10.91 \pm 6.10$ & $10.96 \pm 6.27$ & NS \\
\hline Post-op & $14.89 \pm 5.85$ & $21.33 \pm 5.85$ & $<0.005$ \\
\hline
\end{tabular}

Values are mean $\pm \mathrm{SD}$; NS not significant.

Before surgery in-group 1, the focal lordosis angle was 10.91 and 10.96 in-group 2, and in both group, it significantly increased to 14.89 degree $(\mathrm{P}<0.001)$ and 21.33 degree $(\mathrm{P}<0.001)$ in consecutively. Both groups did not have many significant radiological outcomes (All radiological report is mentioned in Table 3).

\section{Surgical complications}

In both group, no significant complication was observed after the surgery (i.e pulmonary embolus, deep vein thrombosis, hematoma collection in the wound, and incision site infection). Some simple post-surgical complication was seen in both groups $1 \& 2$. In group 1 , there were two patients who had problem with wound infection after surgery that was managed by debridement and by recurrent care provided to the incision site. There were two patients who complained about neuropathic pain in group 1. Also, few patients complained of right leg numbness for about three months but it was covered by some local ointment and oral medication. There were three patients in-group 2 who had tear of dura which was fixed at the time of surgery, and in two cases there was leakage of CSF up to 2 weeks after surgery but halted without re-surgery with some conservative treatment. No cases for recurrent need of surgery were needed and both groups were managed with local and oral medication.

\section{Discussion}

There are different types of surgical method or techniques that have been developed in past years to achieve fusion and reduction for the deformity of isthmic spondylolisthesis [45-50], but it is difficult to define the ideal surgical strategy for IS in adults based on the published data [51]. Each procedure has its own advantages and disadvantages; the basic principle of surgical treatment is decompression and stabilization. In various studies, some Surgeon [51-53] showed that in case of severe spondylolisthesis, it is better to fuse in situ then reduction procedure in the long bone. However, for slipped vertebrae extended at one or two level, usually fusion in situ is performed [51,52,54]. De Wald et al. [55] suggested that the goals spondylolsis hesistreatment by surgical method were fusion as less segments motion as possible, sagittal balance restoration at lumbar spine, and disk space fusion in case of competent absent. Due to performance of fusion in situ, vertebrae are slipped at one/ two levels of segments fusion at normal motion [56,57]. It has been supported by many surgeons that slipped vertebrae reducing to the sagittal balance of lumbar spine for IS [45,58-60]. In a long-term prospective study, Cunningham et al. find that improved sagittal alignment or rate of fusion may result in better outcomes [61]. Also, slip reduction and the sagittal balance restoration can be required for the long run by preventing premature disk degeneration at very close surface $[60,62]$. With the development of very less deformity of spondylolisthetic, there are different surgical procedure and instrumentation that restore spinal balance. To fuse as few motion segments as possible in IS without degenerative disease at the adjacent level, mono- segmental surgical treatment is advocated $[44,63]$.

In this current study, we tried to compare inter body fusion (PLIF/TLIF) with circumferential fusion (PLF+TLIF/PLIF) procedure. Inter body fusion is a common and accepted surgical approach to treat spondylolisthesis. The main advantage of the inter body fusion is nerve root decompression, slip reduction, and postero lateral stabilization can all be performed through a single posterior incision. This procedure was found to have significantly fewer complications, anterior inter body support, postero lateral stabilization, visualization and exiting nerve roots decompression, reduction of the anterolisthesis shorter operating room times, shorter duration of hospital stays, less blood loss, and lower overall costs [64,65]. Given these considerations, it would seem that the PLIF/TLIF is, in many ways, an ideal procedure for isthmic spondylolisthesis.

However, the ability to reduce forward translation, increase disk height, and restore sagittal alignment with the TLIF/PLIF procedure has not been specifically reported. In our group of 45 adult patients affected by isthmic spondylolisthesis, we found a reduction of the anterolisthesis and restoration of inter vertebral height. Surprisingly, however, the slip angle was not suggestively different (Table 3).

Another technique- circumferential fusion (PLF+TLIF/PLIF) explained by some authors has a better result. Severe spinal deformities were successfully treated with combined anterior/ posterior procedures [66-69]. Encouraged by these records and as suggested from the results known from Louis' et al study in 1980, we decided to expand the indication for this surgical procedure.

Circumferential fusion gives the advantage of perfect stability by reconstruction of all three columns of the spine and optimum decompression of all parts of the spinal canal. These factors have to be weighed against the theoretically higher risk of complications and the need for a high degree of expertise in the operative technique in such extensive procedures. Although Louis, who was familiar with the anterior/posterior fusions, denied that they carry a higher complication rate than single anterior or posterior procedures [70], he admitted that a high level of surgical skill is mandatory.

The results of this comparative study show that a single-stage anterior/posterior inter body fusion of the spine provides similar results and a lower complication rate than the two-stage procedure. In addition, the patient's hospital stay can be reduced, with quicker rehabilitation to ambulatory status. Thus, the overall cost of treatment may be reduced by the single-stage procedure. Similar results are reported by Louis [70], who compared the single- stage posterior procedure (78\% satisfactory results) with combined anterior/posterior lumbosacral fusions (79\% satisfactory results). 
In addition, the introduction of transpedicular fixation devices [71-78] allows a reduction in the number of fused segments, especially in cases of spondylolysis and spondylolisthesis. The saving of healthy segments seems to be a distinct advantage compared to the "long rod technique." With cantilever systems such as the internal fixator $[75,76,78-80]$, or with unsatisfactory outcome were treated because of failed treatment for back syndrome (five patients) and deformity after fracture (two patients).

Many possibility and its benefits of reduction had been advocated by many authors. In this current presenting series, inter vertebral disk height, the slippage, focal lordosis in-group one and two were corrected similar to each other. However, the result of clinical outcomes in two different groups did not show significant differences in findings. According to results of both group, similar clinical outcomes in patients treated with instrumented PLIF/ TLIF or performance- with or without instrumentation for the spondylolisthesis. This study had some limitations, as there was large amount of patients with low-grade spondylolisthesis. Our on- going study, we compared these two techniques for highgrade spondylolisthesis. In low-grade spondylolisthesis, there is rare spinal imbalance; in this study long sagittal alignment is not included. This study is limiting, as it will not allow an understanding of the relationship of Overall sagittal balance will not allow an understanding of the relationship of overall sagittal balance and outcomes. In our analysis, for the surgical management of isthmic spondylolisthesis, we indicated that combined approaches circumferential fusion (PLF+TLIF/PLIF) with pedicle screw fixation have no significant clinical outcomes in comparison with Inter body fusion (PLIF/TLIF) alone [81-85].

\section{Conclusion}

In our group of 84 patients, we correlate radiographic findings and clinical outcome in patients undergoing inter body versus circumferential fusion with isthmic spondylolisthesis. In conclusion, our retrospective cohort study suggested that no statistically significant difference was found in terms of postoperative JOA score, VAS leg and back score, blood loss, complication rate, postoperative ODI, and postoperative clinical satisfaction between inter body fusion (PLIF/TLIF) compared to circumferential fusion (PLF+TLIF/ PLIF). Moreover, both techniques led to similar surgical outcomes and complication during follow-up. Thus, these results suggest that both procedures are equally effective for the treatment of isthmic spondylolisthesis.

\section{References}

1. Bick EM (1964) An essay on the history of spine fusion operations. Clin Orthop Relat Res 35: 9-15.

2. Hibbs RA (2007) An operation for progressive spinal deformities: a preliminary report of three cases from the service of the orthopaedic hospital. 1911. Clin Orthop Relat Res 460: 17-20.

3. Albee FH (2007) Transplantation of a portion of the tibia into the spine for Pott's disease : a preliminary report 1911. Clin Orthop Relat Res 460: 14-16.
4. Mehdian SM, Arun R, Jones A, Cole AA (2005) Reduction of severe adolescent isthmic spondylolisthesis: a new technique. Spine (Phila Pa 1976) 30(19): E579-E584.

5. Sears W (2005) Posterior lumbar interbody fusion for lytic spondylolisthesis: restoration of sagittal balance using insert-androtate interbody spacers. Spine J 5(2): 161-169.

6. Morelos O, Pozzo AO (2004) Selective instrumentation, reduction and repair in low-grade degenerative spondylolisthesis. Int Orthop 28(3): 180-182.

7. Dick WT, Schnebel B (1988) Severe spondylolisthesis: reduction and internal fixation. Clin Orthop Relat Res 232: 70-79.

8. Poussa M, Remes V, Lamberg $T$ (2006) Treatment of severe spondylolisthesis in adolescence with reduction or fusion in situ: longterm clinical, radiologic, and functional outcome. Spine (Phila Pa 1976) 31(5): 583-590.

9. Poussa M, Schlenzka D, Seitsalo S, Ylikoski M, Hurri H, et al. (1993) Surgical treatment of severe isthmic spondylolisthesis in adolescents: reduction or fusion in situ. Spine (Phila Pa1976) 18(7): 894-901.

10. Molinari RW, Bridwell KH, Lenke LG, Ungacta FF, Riew KD (1999) Complications in the surgical treatment of pediatric high -grade, isthmic dysplastic spondylolisthesis. A comparison of three surgical approaches. Spine (Phila Pa 1976) 24(16): 1701-1711.

11. Cloward B (1981) Spondylolisthesis: treatment by laminectomy and posteriorinterbody fusion. Clin Orthop Relat Res (154): 74-82.

12. Kalichman L, Kim DH, Li L, Guermazi A, Berkin V, et al. (2009) Spondylolysis and spondylolisthesis: prevalence and association with low back pain in the adult community-based population. Spine (Phila Pa 1976) 34(2): 199-205.

13. Majid K, Fischgrund JS (2008) Degenerative lumbar spon- dylolisthesis: trends in management. J Am Acad Orthop Surg 16(4): 208-215.

14. Jones TR, Rao RD (2009) Adult isthmic spondylolisthesis. J Am Acad Orthop Surg 17(10): 609-617.

15. Yong Ping Ye, Hao Xu, Dan Chen (2013) Comparison between posterior lumbar interbody fusion and posterolateral fusion with transpedicular screw xation for isthmic spondylolithesis: a meta-analysis Arch Orthop Trauma Surg 133(12): 1649-1655.

16. Kwon BK, Berta S, Daffner SD, Vaccaro AR, Hilibrand AS, et al. (2003) Radiographic analysis of transforaminal lumbar interbody fusion for the treatment of adult isthmic spondylolisthesis. J Spinal Disord Tech 16(5): 469- 476

17. Jacobs WC, Vreeling A, De Kleuver M (2005) Fusion for low-grade adult isthmic spondylolisthesis: a systematic review of the literature. Eur Spine J 15(4): 391-402.

18. Kwon BK, Hilibrand AS, Malloy K, Savas PE, Silva MT, et al. (2005) A critical analy- sis of the literature regarding surgical approach and outcome for adult low-grade isthmic spondylolisthesis. J Spinal Disord Tech 18 Suppl: S30-S40.

19. Cloward RB (1953) The treatment of ruptured lumbar intervertebral discs by ventral fusion: indications, operative technique, after care. J Neurosurg 10(2): 154-168.

20. Lin PM (1977) A technical modification of Cloward's posterior lumbar interbody fusion. Neurosurgery 1(2): 118-124.

21. Grob D, Scheier HJ, Dvorak J, Siegrist H, Rubeli M, et al. (1991) Circumferential fusion of the lumbar and lumbosacral spine. Arch Orthop Trauma Surg 111: 20-25.

22. Humphreys SC, Hodges SD, Patwardhan AG, Eck JC, Murphy RB, et al. (2001) Comparison of posterior and transforaminal approaches to lumbar interbody fusion. Spine (Phila Pa 1976) 26(5): 567-571. 
23. Linson MA, Williams H (1991) Anterior and combined anteroposterio fusion for lumbar disc pain. A preliminary study. Spine 16(2): 143-145.

24. Suk SI, Lee CK, Kim WJ, Lee JH, Cho KJ, et al. (1997) Adding posterior lumbar interbody fusion to pedicle screw fixation and posterolateral fusion after decompression in spondylolytic spondylolisthesis. Spine 22(2): 210-219.

25. Kozak JA, O'Brien JP (1990) Simultaneous combined anterior and posterior fusion: An independent analysis of a treatment for the disabled low back pain patient Spine (Phila Pa 1976) 15(4): 322-328.

26. Anekstein Y, Brosh T, Mirovsky Y (2007) Intermediate screws in short segment pedicular fi xation for thoracic and lumbar fractures: A biomechanical study. J Spinal Disord Tech 20(1): 72-77.

27. Guven O, Kocaoglu B, Bezer M, Aydin N, Nalbantoglu U (2009) The use of screw at the fracture level in the treatment of thoracolumbar burst fractures. J Spinal Disord Tech 22(6): 417-421.

28. Macki M, Bydon M, Weingart R, Sciubba D, Wolinsky JP, Gokaslan ZL (2015) Posterolateral fusion with inter body for lumbar spondylolisthesis is associated with less repeat surgery than posterolateral fusion alone. Clin Neurol Neurosurg 138: 117-123.

29. Heary RF, Bono CM (2002) Circumferential fusion for spondylolisthesis in the lumbar spine Neurosurg Focus 13(1): 1-12.

30. Lin PM (1977) A technical modification of Cloward's posterior lumbar interbody fusion. Neurosurgery 1(2): 118-124.

31. Harms J, Rolinger H (1982) A one-stage procedure in operative treatment of spondylolisthesis: dorsal traction-reposition and anterior fusion. Z Orthop Ihre Grenzgeb 120(3): 343-347.

32. Deyo RA, Gray DT, Kreuter W, Mirza S, Martin BI (2005) United States trends in lumbar fusion surgery for degenerative conditions. Spine (Phila Pa 1976) 30(12): 1441-1445.

33. Z Drezner, PM Hahn, ÉD Taillard (2005) Recent advances for the quadratic assignment problem with special emphasis on instances that are difficult for meta-heuristic methods. Annals of Operations Research 139(1): 65-94.

34. Taillard W (1954) Le spondylolisthesis chez l'enfant et l'adolescent (etude 50 cas). Acta Orthopaedica Scandinavica 24(2): 115-144.

35. Meyerding HW (1956) Spondylolisthesis; surgical fusion of lumbosacral portion of spinal column and interarticular facets; use of autogenous bone grafts for relief of disabling backache. J Int Coll Surg 26(5 Part 1): 566-591.

36. Cobb J (1948) Outline for the study of scoliosis. In: Edwards JW (Ed.), Instructional course lectures. The American Academy of Orthopedic Surgeons, USA, pp. 261-275.

37. Kwon BK, Berta S, Daffner SD, Vaccaro AR, Hilibrand AS, et al. (2003) Radiographic analysis of transforaminal lumbar interbody fusion for the treatment of adult isthmic spondylolisthesis. J Spinal Disord Tech 16(5): 469-476.

38. Anekstein Y, Brosh T, Mirovsky Y (2007) Intermediate screws in short segment pedicular fi xation for thoracic and lumbar fractures: A biomechanical study. J Spinal Disord Tech 20(1): 72-77.

39. Guven O, Kocaoglu B, Bezer M, Aydin N, Nalbantoglu U (2009) The use of screw at the fracture level in the treatment of thoracolumbar burst fractures. J Spinal Disord Tech 22(6): 417-421.

40. Okuda S, Oda T, Miyauchi A, Haku T, Yamamoto T, et al. (2006) Surgica outcomes of posterior lumbar inter body fusion in elderly patients. J Bone Joint Surg Am 88(12): 2714-2720.

41. Greenough CG, Peterson MD, Hadlow S, Fraser RD (1998) Instrumented posterolateral lumbar fusion. Results and comparison with anterior interbody fusion. Spine 23(4): 479-486.
42. Poussa M, Remes V, Lamberg T, Tervahartiala P, Schlenzka D, et al. (2006) Treatment of severe spondylolisthesis in adolescence with reduction or fusion in situ: long-term clinical, radiologic, and functional outcome. Spine (Phila Pa 1976) 31(5): 583-592.

43. Zhao J, Hou T, Wang X, Ma S (2003) Posterior lumbar interbody fusion using one diagonal fusion cage with transpedicular screw/rod fixation. Eur Spine J 12(2): 173-177.

44. Sears W (2005) Posterior lumbar interbody fusion for lytic spondylolisthesis: restoration of sagittal balance using insert-androtate interbody spacers. Spine J 5(2): 161-169.

45. Johnson JR, Kirwan EO (1983) The long-term results of fusion in situ for severe spondylolisthesis. J Bone Joint Surg (Br) 65(1): 43-46.

46. Harry LS, Matthew JG (2005) High-grade isthmic dysplastic spondylolisthesis: monosegmental surgical treatment. Spine 30(6S): S42-S48.

47. Spruit M, Pavlov PW, Leitao J, De Kleuver M, Anderson PG, et al. (2002) Posterior reduction and anterior lumbar interbody fusion in symptomatic low-grade adult isthmic spondylolisthesis: short term radiological and functional outcome. Eur Spine J 11(5): 428-433.

48. Smith J, Deviren V, Berven S, Kleinstueck F, Bradford D (2001) Clinical outcome of trans-sacral interbody fusion after partial reduction for high-grade L5-S1 spondylolisthesis. Spine (Phila Pa 1976) 26(20): 22272234

49. Mehdian SH, Arun R (2011) A new three-stage spinal shortening procedure for reduction of severe adolescent isthmic spondylolisthesis: a case series with medium- to long-termfollow-up. Spine (Phila Pa 1976) 36(11): E705-E711.

50. Poussa M, Remes V, Lamberg T, Tervahartiala P, Schlenzka D, et al. (2006) Treatment of severe spondylolisthesis in adolescence with reduction or fusion in situ: long-term clinical, radiologic, and functional outcome. Spine (Phila Pa 1976) 31(5): 583-592.

51. Zhao J, Hou T, Wang X, Ma S (2003) Posterior lumbar interbody fusion using one diagonal fusion cage with transpedicular screw/rod fixation. Eur Spine J 12(2): 173-177.

52. Johnson JR, Kirwan EO (1983) The long-term results of fusion in situ for severe spondylolisthesis. J Bone Joint Surg (Br) 65(1): 43-46.

53. Grzegorzewski A, Kumar SJ (2000) In situ posterolateral spine arthrodesis for grades III, IV, and V spondylolisthesis in children and adolescents. J Pediatr Orthop 20(4): 506-511.

54. DeWald R. Spondylolisthesis. In: Bridwell K, DeWald R (Eds.), The textbook of spinal surgery, ( $\left.2^{\text {nd }} e d n\right)$, Lippincott-Raven, Philadelphia, USA, pp. 1202-1210.

55. Poussa M, Remes V, Lamberg T, Tervahartiala P, Schlenzka D, et al. (2006) Treatment of severe spondylolisthesis in adolescence with reduction or fusion in situ: long-term clinical, radiologic, and functional outcome. Spine (Phila Pa 1976) 31(5): 583-592.

56. Grzegorzewski A, Kumar SJ (2000) In situ posterolateral spine arthrodesis for grades III, IV, and V spondylolisthesis in children and adolescents. J Pediatr Orthop 20(4): 506-511.

57. Spruit M, Pavlov PW, Leitao J, De Kleuver M, Anderson PG, et al (2002) Posterior reduction and anterior lumbar interbody fusion in symptomatic low-grade adult isthmic spondylolisthesis: short-term radiological and functional outcome. Eur Spine J 11(5): 428-433.

58. Mehdian SH, Arun R (2011) A new three-stage spinal shortening procedure for reduction of severe adolescent isthmic spondylolisthesis: a case series with medium- to long-termfollow-up. Spine (Phila Pa 1976) 36(11): E705-E711.

59. Floman Y, Millgram MA, Ashkenazi E, Smorgick Y, Rand N (2008) Instrumented slip reduction and fusion for painful unstable isthmic spondylolisthesis in adults. J Spinal Disord Tech 21(7): 477-483.

How to cite this article: Gazi S, Md Zakirul H, Dur E S S, Saiful I N, Md Shoriful I, Mohammad A M. Comparison of Simple Lumbar Inter Body Fusion with 
60. Cunningham JE, Elling EM, Milton AH, Robertson PA (2013) What is the optimum fusion technique for adult isthmic spondylolisthesis-PLIF or PLF? A long-term prospective cohort comparisonstudy. J Spinal Disord Tech 26(5): 260-267.

61. Smith J, Deviren V, Berven S, Kleinstueck F, Bradford D (2001) Clinical outcome of trans-sacral interbody fusion after partial reduction for high-grade L5-S1 spondylolisthesis. Spine (Phila Pa 1976) 26(20): $2227-$ 2234 .

62. Mehdian SH, Arun R (2011) A new three-stage spinal shortening procedure for reduction of severe adolescent isthmic spondylolisthesis: a case series with medium-to long-term follow-up. Spine (Phila Pa 1976) 36(11): E705-E711.

63. Hee HT, Castro FP Jr, Majd ME, Holt RT, Myers L (2001) Anterior/ posterior lumbar fusion versus transforaminal lumbar interbody fusion: analysis of complications and predictive factors. J Spinal Disord 14(6): 533-540.

64. Whitecloud TS III, Roesch WW, Ricciardi JE (2001) Transforaminal interbody fusion versus anterior-posterior interbody fusion of the lumbar spine: a financial analysis. J Spinal Disord 14(2): 100-103.

65. Kim JS, Kim Dh, Lee Sh, Park cK, HwangJh, et al. (2010) comparison study of the instru- mented circumferential fusion with instrumented anterior lumbar interbody fusion as a surgical procedure for adult low-grade isthmic spondylolisthesis. World Neurosurg 73(5): 565-571.

66. Poussa M, Remes V, Lamberg T (2006) Treatment of severe spondylolisthesis in adolescence with reduction or fusion in situ: longterm clinical, radiologic, and functional outcome. Spine (Phila Pa 1976) 31(5): 591-592.

67. Zhao J, Hou T, Wang X, Ma S (2003) Posterior lumbar interbody fusion using one diagonal fusion cage with transpedicular screw/rod fixation. Eur Spine J 12(2): 173-177.

68. Johnson JR, KirwanEO (1983) The long-term results of fusion in situ for severe spondylolisthesis. J Bone Joint Surg (Br) 65: 43-46.

69. Grzegorzewski A, Kumar SJ (2000) In situ posterolateral spine arthrodesis for grades III, IV, and V spondylolisthesis in children and adolescents. J Pediatr Orthop 20(4): 506-511.

70. DeWaldR Spondylolisthesis. In: Bridwell K, DeWald R (Eds.), The textbook of spinal surgery, $2^{\text {nd }}(e d n)$. Lippincott-Raven, Philadelphia, USA, pp. 1202-1210.

71. Dewald RL, Faut MM, Taddonio RF, Neuwirth MG (1981) Severe lumbosacral spondylolisthesis in adolescents and children: Reduction and staged circumferential fusion. J Bone Joint Surg [Am] 63A: 619-626.

72. Floman Y, Micheli LJ, Penny JN, Riseborough EJ, Hall JE (1982) Combined anterior and posterior fusion in seventythree spinally deformed patients. Indications, results, complications. Clin Orthop 164: 110-122.

73. Kaneda K, Kazama H, Satoh S, Funjiya M (1986) Follow up study of medial facetectomies and posterolateral fusion with instrumentation in unstable degenerative spondylolisthesis. Clin Orthop Relat Res 203: 159-167.

74. Winter RB (1978) Combined Dwyer and Harrington instrumentation and fusion in the treatment of the selected patients with painful adult idiopathic scoliosis. Spine (Phila Pa 1976) 3(2): 135-141.

75. Louis R (1986) Fusion of the lumbal and sacral spine by internal fixation with screws and plates. Clin Orthop Relat Res 203: 18-33.

76. Aebi M (1988) Correction of degenerative scoliosis of the lumbar spine. A preliminary report. Clin Orthop Relat Res 232: 80-86.

77. Dick W. Innere Fixation von Brust- und Lendenwirbelfrakturen. Aktuelle Probleme in Chirurgie und Orthopfidie, Huber, Berne, Switzerland.

78. Krag MH, Beynnon BD, Pope MH, Frymoyer JW, Haugh LD, et al. An internal fixator for posterior application to short segments of the thoracic, lumbar or lumbosacral spine. Design and testing. Clin Orthop 203: 99.

79. Louis R. Die Chirurgie der Wirbelsiule. Springer, Berlin Heidelberg, New York, USA.

80. Magerl FP (1982) External skeletal fixation of the lower thoracic and the lumbar spine. In Uhthoff HK (ed.), Current concepts of external fixation of fractures. Springer, Berlin Heidelberg, New York, USA, p. 353.

81. Magerl FP (1984) Stabilization of the lower thoracic and lumbar spine with external skeletal fixation. Clin Orthop Relat Res 189: 125-141.

82. Magerl FP. External spinal skeletal fixation. In: Weber BG, Magerl FP (Eds). The external skeletal fixation. Springer, Berlin Heidelberg, New York, USA.

83. Olerud S, Karlstrm G, Sjstrm L (1988) Transpedicular fixation of thoracolumbar vertrebral fractures. Clin Orthop Relat Res 227: 44-51.

84. Camille R, Saillant G, Mazel C (1986) Internal fixation of the lumbar spine with pedicle screw plating. Clin Orthop Relat Res 203: 7-17.

85. Steffee AD, Biscup RS, Sitakowski DJ (1986) Segmental spine plates with pedicle screw fixation: A new internal fixation device for disorders of the lumbar and thoracolumbar spine. Clin Orthop Relat Res (203): 45-53.
Creative Commons Attribution 4.0

International License

For possible submissions Click Here
Submit Article

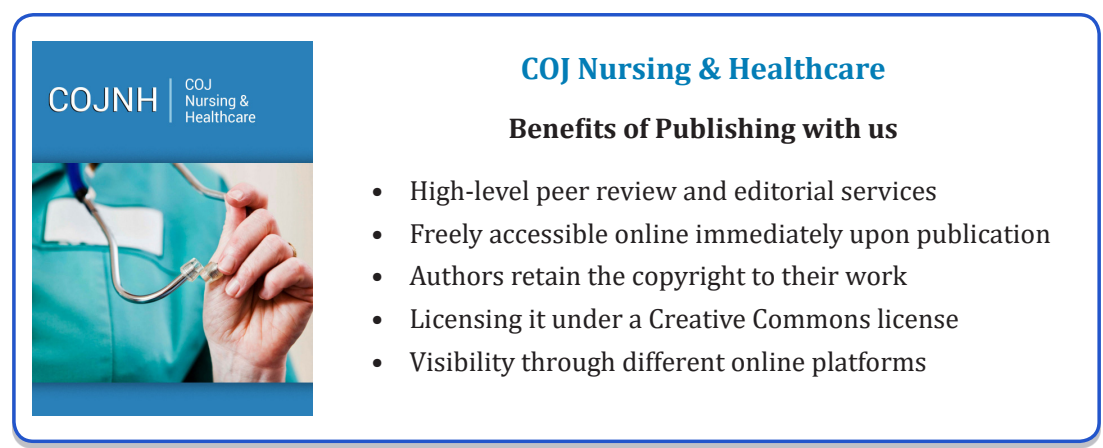

